\title{
PENGUKURAN CAPABILITY LEVEL TATA KELOLA DAN MANAJEMEN TI MENGGUNAKAN COBIT 5.0 PADA PT WELLCOMM RITELINDO PRATAMA
}

\author{
MEASUREMENT OF MANAGEMENT CAPABILITY LEVEL AND IT \\ MANAGEMENT USING COBIT 5.0 IN PT WELLCOMM RITELINDO \\ PRATAMA \\ Aditya Pratama ${ }^{1)}$, Deborah Herby ${ }^{2)}$ \\ ${ }^{1,2)}$ Sistem Informasi/Fakultas Teknologi Informasi dan Komunikasi, Universitas Multimedia Nusantara
}

Diterima 05 Agustus 2019 / Disetujui 18 Agustus 2019

\begin{abstract}
In this study, researchers wanted to find out the level of information technology in the company through measuring the capability level of governance and information technology management at PT Wellcomm Ritelindo Pratama using the COBIT 5.0 framework. There are 3 research methods used, that is: observation, interview, and checklist. The first is to hold discussions about the goals of PT Wellcomm Ritelindo Pratama based on enterprise goals in COBIT 5.0. The second is mapping the company goals / enterprise goals to the IT goals of the company / it goals. Third is to enter into the process in COBIT 5.0. From the calculation results obtained from the process questionnaire is to determine the capability level of the process (target maturity) and whether the process can continue until the last level (5) or must stop at the initial level (1). The final step is to provide recommendations based on the final capability level and target capability level (next level). The results of measuring capability capability management and IT management using COBIT 5.O PT Wellcomm Ritelindo Pratama, found several weaknesses that must be a concern of management in the future. The recommendations given are based on two targets: the target is carried out fully, so that the company can carry out each activity and complete it so that it can be said that the activity is carried out fully, and the target to be able to move up to the next level.

Keyword : level of governance, information technology, COBIT 5, capability level, evaluation, process.
\end{abstract}

\begin{abstract}
ABSTRAK
Dalam penelitian ini, peneliti ingin mengetahui tingkat teknologi informasi di perusahaan melalui pengukuran capability level tata kelola dan manajemen teknologi informasi pada PT Wellcomm Ritelindo Pratama dengan menggunakan kerangka kerja COBIT 5.0. Ada 3 metode penelitian yang digunakan, yaitu : observasi, wawancara, dan checklist. Pertama ialah melakukan diskusi mengenai tujuan PT Wellcomm Ritelindo Pratama berdasarkan enterprise goals pada COBIT 5.0. Kedua dilakukan pemetaan tujuan perusahaan/enterprise goals ke tujuan TI perusahaan/it goals. Ketiga ialah masuk ke dalam proses yang ada di dalam COBIT 5.0. Dari hasil perhitungan yang telah diperoleh dari kuesioner proses itu ialah untuk menentukan capability level proses (target maturity) dan apakah proses dapat berlanjut sampai level terakhir (5) atau harus berhenti di level awal (1). Langkah terakhir ialah memberikan rekomendasi berdasarkan hasil akhir capability level dan target capability level (level selanjutnya). Hasil pengukuran capability level tata kelola dan manajemen TI menggunakan COBIT 5.0 PT Wellcomm Ritelindo Pratama, di temukan beberapa kelemahan yang harus menjadi perhatian manajemen di masa yang akan datang. Hasil rekomendasi yang diberikan berdasarkan dua target yaitu target dilakukan sepenuhnya, agar perusahaan dapat melakukan tiap aktifitas dan menyelesaikannya hingga dapat dikatakan aktifitas tersebut dilakukan sepenuhnya, serta target untuk dapat naik ke level berikutnya.
\end{abstract}

Kata Kunci: Tata kelola, Teknologi informasi, COBIT 5, Capability Level, Evaluasi, Proses.

\footnotetext{
*Korespondensi Penulis:

E-mail: adityapratama.umn@gmail.com
} 


\section{PENDAHULUAN}

Untuk dapat memenuhi tata kelola dan manajemen teknologi informasi yang baik dibutuhkan suatu standar yang efektif yaitu dengan menerapkan audit dengan menggunakan framework COBIT (Control Objective for Information and Related Technology). COBIT dikembangkan oleh IT Governance Institute (ITGI) yang merupakan bagian dari Information Systems Audit and Control Association (ISACA).

Pengukuran capability level teknologi informasi dan manajemen teknologi informasi pada suatu perusahaan sangat penting. Karena itu, PT Wellcomm Ritelindo Pratama yang merupakan suatu perusahaan yang bergerak di bidang penjualan aksesoris handphone dan gadget perlu juga melakukan evaluasi atas manajemen dan tata kelolanya. PT Wellcomm menjadi leader brand penjualan aksesoris handphone dan gadget sejak tahun 1996. Bapak Sutrino Chandra selaku Direktur TI di PT Wellcomm Ritelindo Pratama ingin mengetahui sejauh mana tingkat tata kelola dan manajemen informasi yang ada pada perusahaan mereka.

COBIT merupakan framework Audit Teknologi Informasi (IT) yang dibuat oleh ISACA ( Information System Audit and Control Association). COBIT pertama diterbitkan pada tahun 1996, kemudian dirilis edisi kedua pada tahun 1998. Pada tahun 2000 kemudian di rilis COBIT 3.0, dan pada tahun 2005 dirilis COBIT 4.0. Pada tahun 2007 COBIT merilis versi 4.1, dan pada tahun 2012 COBIT Merilis COBIT versi paling baru yaitu versi 5.0. COBIT dilengkapi dengan balanced scorecard dan dapat dipakai sebagai acuan audit IT, yang disejajarkan dengan standar industri seperti ITIL, CMM, BS779, dan ISO9000. COBIT menjabarkan bahwa keputusan bisnis yang baik harus didasarkan pada pengetahuan yang berasal dari informasi yang relevan, komprehensif dan tepat waktu.

Menurut Gondodiyoto (2007) COBIT adalah sekumpulan dokumentasi best practice untuk tata kelola IT yang dapat membantu auditor, pengguna sistem, dan manajemen dalam menjembatani risiko organisasi, kebutuhan pengendalian, dan masalah-masalah teknis TI (Gondodiyoto, 2007).

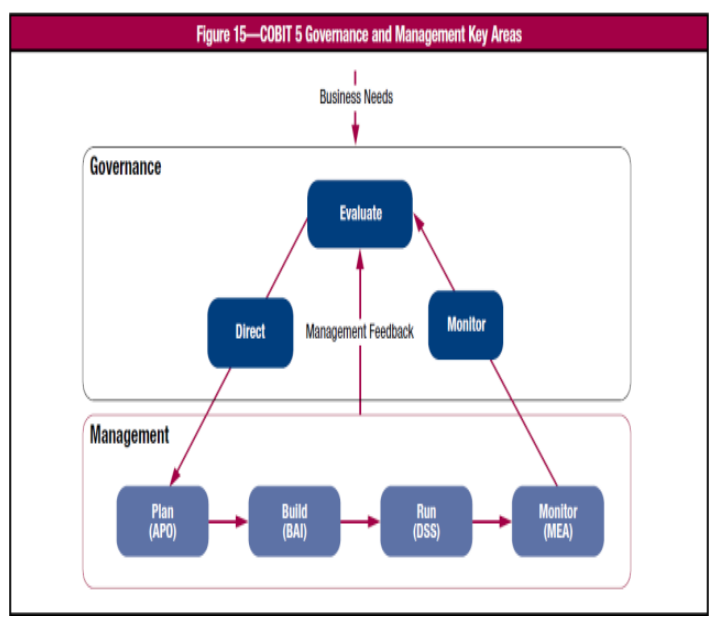

Gambar 1 Proses Model Cobit

(Sumber : A Business Framework for the Governance and Management of Enterprise IT. ISACA. 2012. p32.) (ISACA, 2012).

COBIT 5 memiliki 2 area : tata kelola dan manajemen.

\section{METODE PENELITIAN}

\section{A. Gambaran Umum Objek Penelitian}

Penelitian audit tata kelola teknologi informasi dilakukan PT Wellcomm Ritelindo Pratama. PT Wellcomm Ritelindo Pratama ini merupakan perusahaan yang melakukan penjualan aksesoris handphone yang beralamat di Komplek Alam Sutera Niaga 3A No.20 Jl. Raya Serpong -Tangerang KM.8 - Serpong, Tangerang 15324. Indonesia.

\section{B. Metode Penelitian}

Metode penelitian yang digunakan ialah observasi, wawancara, dan checklist yang dilakukan melalui proses pada chart di Gambar 2. 


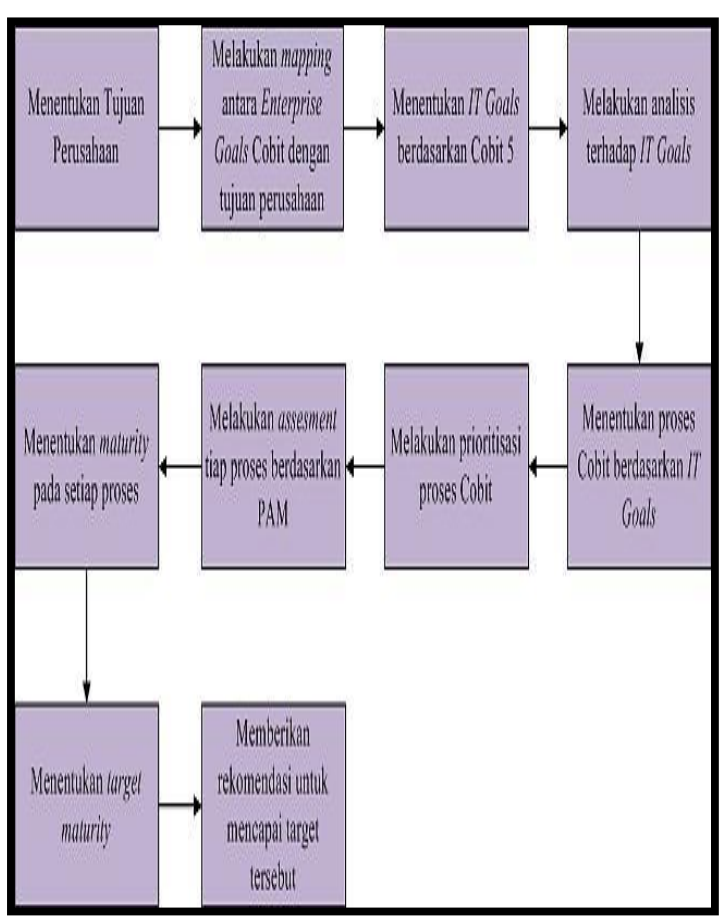

Gambar 2 Metode Penelitian

Pertama ialah melakukan diskusi mengenai tujuan perusahaan berdasarkan enterprise goals pada COBIT 5.0. Kedua dilakukan pemetaan tujuan perusahaan / enterprise goals ke tujuan TI perusahaan / it goals. ketiga ialah masuk ke dalam proses yang ada di dalam COBIT 5.0 :

- Melakukan pemetaan / mapping dari tujuan TI perusahaan / it goals ke proses cobit.

- Membatasi proses yang akan dibahas ke tahap selanjutnya.

- Menggunakan PAM (Process Assessment Model) menyelesaikan evaluasi proses cobit melalui 5 level.

- Pengerjaan proses cobit dilakukan dengan kuesioner dan wawancara.

- Hasil dari kuesioner di hitung untuk dimasukkan ke PAM.

Dari hasil perhitungan yang diperoleh dari kuesioner proses itu ialah untuk menentukan capability level proses (target maturity) dan apakah proses dapat berlanjut sampai level terakhir (5) atau harus berhenti di level awal (1). Langkah terakhir ialah memberikan rekomendasi berdasarkan hasil akhir capability level dan target capability level (level selanjutnya).

Setelah melakukan prioritas proses COBIT. Kemudian melakukan assesment tiap proses berdasarkan PAM untuk menyelesaikan evaluasi proses COBIT melalui 5 level.

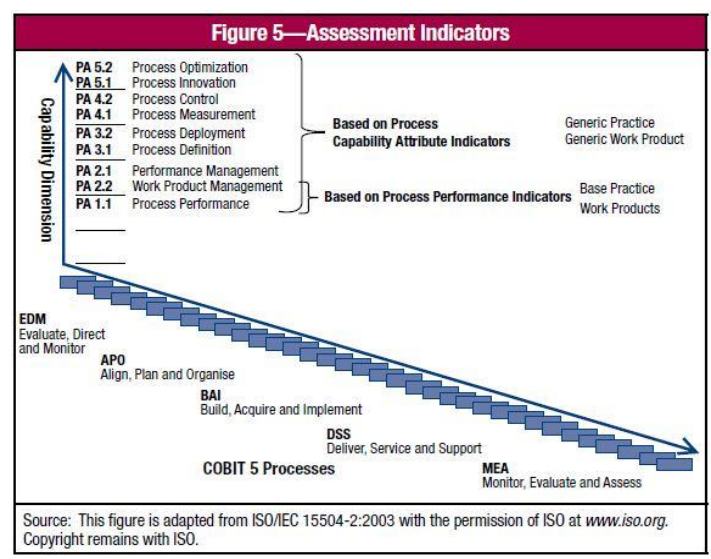

\section{Gambar 3 Level PAM}

(Sumber : Process Assessment Model (PAM): Using COBIT® 5. ISACA. 2013. P114.) (ISACA, 2013).

\section{Kuesioner Proses}

Kuesioner yang ada dalam proses ini didapat dari aktifitas setiap proses atau disebut dengan best practices. Dalam checklist ini dibagi ke dalam 4 penilaian yaitu: "tidak dilakukan, "dilakukan Sebagian kecil", "dilakukan sebagian besar", dan "dilakukan sepenuhnya". Kemudian setelah mendapatkan hasil checklist, akan dilakukan penghitungan berdasarkan standar nilai yang ada di PAM (Process Assessment Model). Berdasarkan nilai yang sudah ditetapkan perhitungan di kuesioner dapat dilakukan seperti tabel dibawah ini.

Tabel 2. Penilaian checklist 


\begin{tabular}{|c|c|}
\hline Nama Nïla Kuesioner & Nilai \\
\hline Tidak Dilakukan & $0-15 \%$ \\
\hline Dilakukan Sebagian Kecil & $15-50 \%$ \\
\hline Dilakukan Sebagian Besar & $50-85 \%$ \\
\hline Dilakukan Sepenuhnya & $85-100 \%$ \\
\hline
\end{tabular}

Tabel 3. Contoh tabel kuesioner yang sudah diisi.

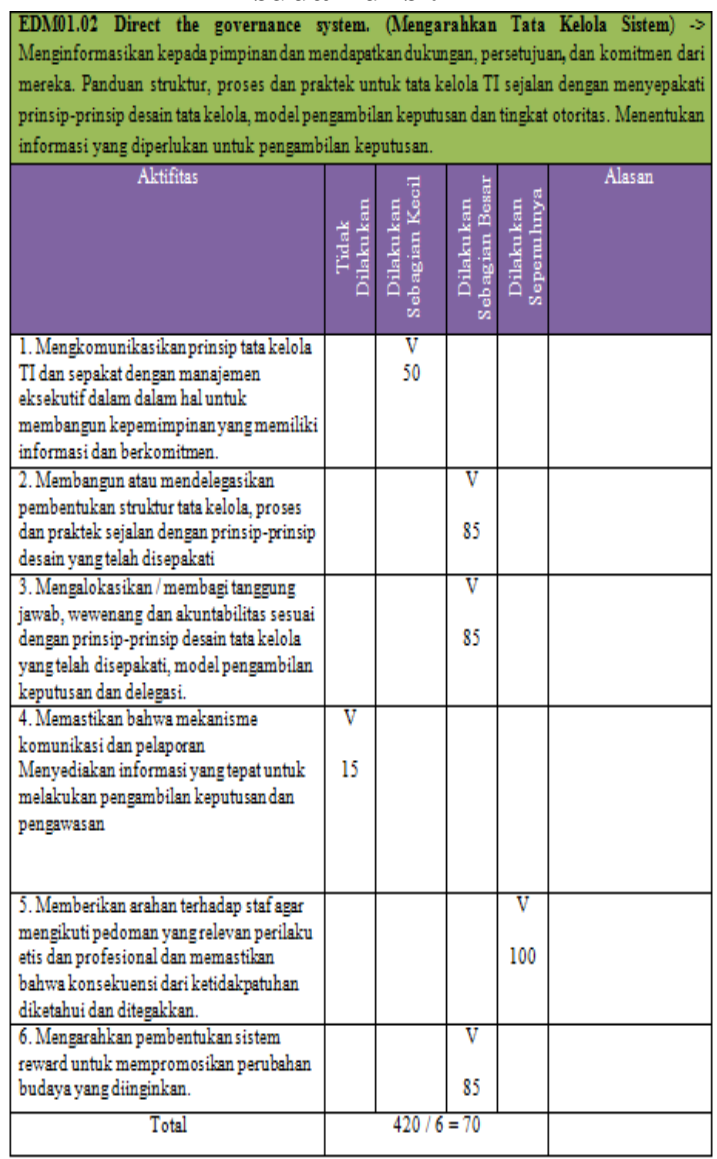

Hasil yang didapat dari perhitungan kuesioner menghasilkan nilai capability level (tingkat level) dimana proses berada. Hasil perhitungan kuesioner nya harus (>) dari $85 \%$ agar dapat ke naik level selanjutnya, berdasarkan Assessor Guide : Using COBIT® 5. ISACA. 2013. P19 " Note that a purpose can be rated at one level with an attribute only "largely achieved". However, the attribute will need to be fully achieved to be rated at the next level."

Artinya bahwa tujuan dapat dinilai pada tingkat satu dengan atribut hanya "dicapai sebagian besar". Namun, atribut akan dapat dicapai sepenuhnya ketika dinilai di tingkat berikutnya.

\section{HASIL DAN PEMBAHASAN}

\section{A. Identifikasi Enterprise Goals}

Pada tahap awal ini Penulis akan melakukan identifikasi tujuan dan sasaran tata kelola IT pada PT. WELLCOMM yang disesuaikan dengan enterprise goals yang terdapat pada COBIT 5. Perusahaan mengisi lembar enterprise goals dengan mengurutkan sesuai dengan prioritas terpenting perusahaan sampai yang prioritas paling kecil berdasarkan hasil diskusi Penulis dengan perusahaan.

Tabel 4. Enterprise Goals

\begin{tabular}{|c|c|c|c|}
\hline \multicolumn{3}{|c|}{$\begin{array}{l}\text { Enterprise COBIT } 5.0 \\
\end{array}$} & \multirow{2}{*}{\begin{tabular}{|c}
$\begin{array}{l}\text { Enterprise } \\
\text { Goals }\end{array}$ \\
1 \\
\end{tabular}} \\
\hline \multirow[t]{5}{*}{ Financial } & 1 & \begin{tabular}{|l|} 
Stakeholder value of business investments \\
Nilai Investasi Bisnis Stakeholder
\end{tabular} & \\
\hline & 2 & $\begin{array}{l}\text { Porffolio of compestitive products and services } \\
\text { Portofolio Produl dan Jasa yang kompetitif }\end{array}$ & 13 \\
\hline & 3 & $\begin{array}{l}\text { Managed business risk (saffguarding of assstis) } \\
\text { Mengelola Risiko bisnis(Pengamanan Aset) }\end{array}$ & 7 \\
\hline & 4 & $\begin{array}{l}\text { Compliance with extemal lawis and regulations } \\
\text { Kepatuhan terhadap Hukum dan PeraturanEkstemal }\end{array}$ & 2 \\
\hline & 5 & $\begin{array}{l}\text { Financial transparency } \\
\text { Transparansi Keuangan }\end{array}$ & 15 \\
\hline \multirow[t]{5}{*}{ Customer } & 6 & $\begin{array}{l}\text { Customer-oriented service culture } \\
\text { Budaya Layanan yang berorientasi kapada pelangegan }\end{array}$ & 5 \\
\hline & 7 & $\begin{array}{l}\text { Business service conthuity and availability } \\
\text { Kontinuitas dan ketersediann Layanan Bisnis }\end{array}$ & 6 \\
\hline & 8 & $\begin{array}{l}\text { Ag ils responses to a changing business environtment } \\
\text { Tangegpan yang capast terhadap perubahan lingkungan bisnis }\end{array}$ & 11 \\
\hline & 9 & $\begin{array}{l}\text { Information-based strategic decision making } \\
\text { Pengambilan keputusan strategi berbasis Informasi }\end{array}$ & 4 \\
\hline & 10 & $\begin{array}{l}\text { Optimisation of service delivery costs } \\
\text { Optimalisasi Biaya Pelayanan }\end{array}$ & 12 \\
\hline \multirow[t]{5}{*}{ Internal } & 11 & $\begin{array}{l}\text { Optimisation of business process functionality } \\
\text { Optimalisasi Fungsi Proses Bisnis }\end{array}$ & 8 \\
\hline & 12 & \begin{tabular}{|l|} 
Optimisation of business processs costs \\
Optimalisasi Biays Proses Bisnis
\end{tabular} & 9 \\
\hline & 13 & $\begin{array}{l}\text { Managed business changes programmes } \\
\text { Mengelola Perubshan Program Bisnis }\end{array}$ & 17 \\
\hline & 14 & \begin{tabular}{|l|} 
Operationaland staff productivity \\
Produltivitas Staf dan Operasional
\end{tabular} & 10 \\
\hline & 15 & $\begin{array}{l}\text { Compliance with intermalpolicies } \\
\text { Kapatuhan terhadap kebijakan internal }\end{array}$ & 14 \\
\hline \multirow{2}{*}{$\begin{array}{l}\text { Learning } \\
\text { and } \\
\text { Growth }\end{array}$} & 16 & $\begin{array}{l}\text { Skilled and motivated peopls } \\
\text { Orang yang terampil dan termotivasi }\end{array}$ & 3 \\
\hline & 17 & \begin{tabular}{|l|} 
Product and business innovation culture \\
Budaya Inovasi Produl dan Bisnis
\end{tabular} & 16 \\
\hline
\end{tabular}

\section{B. Identifikasi IT Goals}

Setelah melakukan identifikasi enterprise goals, selanjutnya adalah melakukan identifikasi IT goals. 
Tabel 5 Pemetaan IT goals Berdasarkan Enterprise Goals.

\begin{tabular}{|c|c|c|c|c|}
\hline \multicolumn{3}{|r|}{ Enterprise COBIT 5.0} & \multirow{2}{*}{$\begin{array}{c}\begin{array}{c}\text { Enterprise } \\
\text { Goals }\end{array} \\
1\end{array}$} & \multirow{2}{*}{$\begin{array}{l}\text { IT Related } \\
\text { Goals } \\
1,3,5,7,11,13\end{array}$} \\
\hline \multirow[t]{3}{*}{ Financial } & 1 & $\begin{array}{l}\text { Stakeholder value of business investments } \\
\text { Nilai Investasi Bisnis Stakeholder }\end{array}$ & & \\
\hline & 4 & $\begin{array}{l}\text { Compliance with external laws and } \\
\text { regulations } \\
\text { Kepatuhan terhadap Hukumdan Peraturan } \\
\text { Ekstemal }\end{array}$ & 2 & 2,10 \\
\hline & 16 & $\begin{array}{l}\text { Skilled and motivated people } \\
\text { Orang yang terampil dan termotivasi }\end{array}$ & 3 & 16 \\
\hline \multirow[t]{3}{*}{ Customer } & 9 & $\begin{array}{l}\text { Information-based strategic decision } \\
\text { making } \\
\text { Pengambilan keputusan strategi berbasis } \\
\text { Informasi }\end{array}$ & 4 & 1,14 \\
\hline & 6 & $\begin{array}{l}\text { Customer-oriented service culture } \\
\text { Budaya Layanan yang berorientasikepada } \\
\text { pelanggan }\end{array}$ & 5 & 1,7 \\
\hline & 7 & $\begin{array}{l}\text { Business service continuity and availability } \\
\text { Kontinuitas dan ketersediaan Layanan } \\
\text { Bisnis }\end{array}$ & 6 & $4,10,14$ \\
\hline \multirow[t]{3}{*}{ Internal } & 3 & $\begin{array}{l}\text { Managed business risk (safeguarding of } \\
\text { assets) } \\
\text { Mengelola Risiko bisnis(Pengamanan } \\
\text { Aset) }\end{array}$ & 7 & $4,10,16$ \\
\hline & 11 & $\begin{array}{l}\text { Optimisation of business process } \\
\text { functionality } \\
\text { Optimalisasi Fungsi Proses Bisnis }\end{array}$ & 8 & $1,7,8,9,12$ \\
\hline & 12 & $\begin{array}{l}\text { Optimisation of business process costs } \\
\text { Optimalisasi Biaya Proses Bisnis }\end{array}$ & 9 & $5,6,11$ \\
\hline $\begin{array}{l}\text { Learning and } \\
\text { Growth }\end{array}$ & 14 & $\begin{array}{l}\text { Operational andstaff productivity } \\
\text { Produktivitas Staf dan Operasional }\end{array}$ & 10 & 8,16 \\
\hline
\end{tabular}

\section{Mapping IT Goals ke dalam proses COBIT}

COBIT 5 telah memberikan cara pemetaan enterprise goals ke IT (ISACA, 2013). Dari pemetaan yang telah dilakukan, dapat dilihat $I T$ goals apa saja yang dapat menunjang enterprise goals.

Tabel 6. Pembatasan Mapping IT Goals

\section{Ke Proses COBIT.}

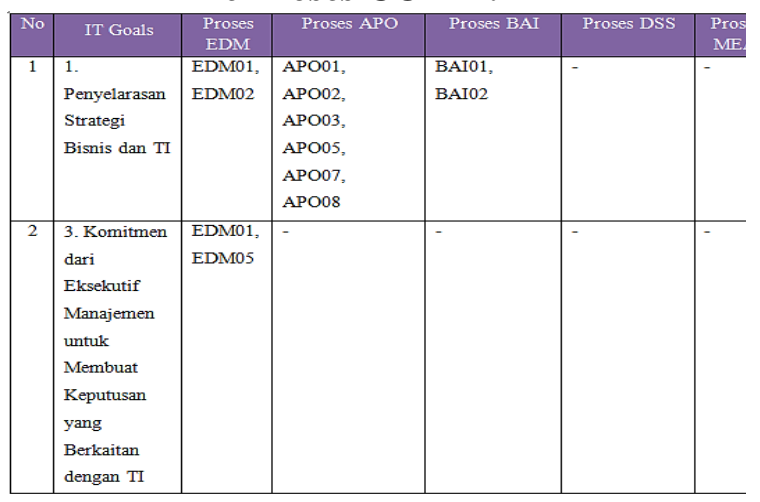

\section{Perhitungan Kuesioner}

Tabel 7 Tabel Total Perhitungan.

\begin{tabular}{|c|c|c|c|c|}
\hline N0 & PROSES & TOTAL & STATUS & KETERANGAN \\
\hline 1 & EDM01 & $85 \%$ & Dilakukan Sepenuhnya & Proses Berlanjut ke Level 2 \\
\hline 2 & EDM02 & $64 \%$ & Dilakukan Sebagian Besar & Proses Berhenti Pada Level 1 \\
\hline 3 & EDM05 & $62 \%$ & Dilakukan Sebagian Besar & Proses Berhenti Pada Level 1 \\
\hline 4 & AP001 & $73,51467 \%$ & Dilakukan Sebagian Besar & Proses Berhenti Pada Level 1 \\
\hline 5 & AP002 & $82,096 \%$ & Dilakukan Sebagian Besar & Proses Berhenti Pada Level 1 \\
\hline 6 & AP003 & $55,384 \%$ & Dilakukan Sebagian Besar & Proses Berhenti Pada Level 1 \\
\hline 7 & AP005 & $58,75 \%$ & Dilakukan Sebagian Besar & Proses Berhenti Pada Level 1 \\
\hline 8 & AP007 & $56,8055 \%$ & Dilakukan Sebagian Besar & Proses Berhenti Pada Level 1 \\
\hline 9 & AP008 & $73,8 \%$ & Dilakukan Sebagian Besar & Proses Berhenti Pada Level 1 \\
\hline 10 & BAI01 & $49,1026 \%$ & Dilakukan Sebagian Kecil & Proses Berhenti Pada Level 1 \\
\hline 11 & BA102 & $54,118 \%$ & Dilakukan Sebagian Besar & Proses Berhenti Pada Level 1 \\
\hline
\end{tabular}

Nilai Tertinggi : EDM01 (85\%)

Nilai Terendah : BAI01 $(49,1026 \%)$

Nilai rata-rata $: 85 \%+65 \%+62 \%+$ $73,51467 \%+82,086 \%+55,384 \%+$ $58,75 \%+56,8055 \%+73,8 \%+49,1026 \%$ $+54,118 \% / 11=\mathbf{6 4 , 9 6 0 9 7 \%}$ (Dilakukan Sebagian Besar)

\section{E. Radar Chart}

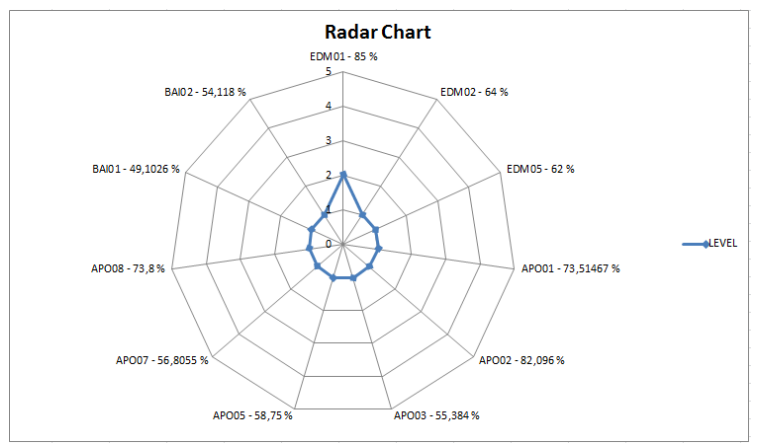

\section{Gambar 4 Radar Chart}

\section{F. Rekomendasi}

Hasil pengukuran capability level tata kelola dan manajemen TI menggunakan COBIT 5.0 PT Wellcomm Ritelindo Pratama, di temukan beberapa kelemahan yang harus menjadi perhatian manajemen di masa yang akan datang. Atas beberapa kelemahan tersebut, maka 
diberikan rekomendasi sebagai koreksi atau langkah perbaikan

\section{Tabel 8. Rekomendasi EDM05.03}

\begin{tabular}{|c|c|}
\hline \multicolumn{2}{|c|}{$\begin{array}{l}\text { EDM05.03 Monitor stakeholder communication. (Memantau komunikasi pemangku } \\
\text { kepentingan (stakehoder) }>\text { Memantau efektivitas komunikasi stakeholder. Menilai } \\
\text { mekanisme untuk memastikan akurasi, kehandalan dan efektivitas, dan memastikan apakah } \\
\text { persyaratan pemangku kepentingan (stakeholder) yang berbeda terpenuhi. }\end{array}$} \\
\hline $\begin{array}{c}\text { EDM } 05.03 \\
\text { Level } 1\end{array}$ & Target Dilakukan Sepenuhnya \\
\hline $\begin{array}{l}\text { 1. Menilai secara berkala efektivitas } \\
\text { mekanisme untuk memastikan keakuratan } \\
\text { dan keandalan pelaporan wajib. }\end{array}$ & $\begin{array}{l}\text { Melakukan review penilaian secara berkala } \\
\text { dalam jangka waktu tertentu berdasarkan peran } \\
\text { dan tanggung jawabnya masing-masing. Laporan } \\
\text { ini digunakan untukmenilai kinerja dari } \\
\text { mekanisme yang ada. }\end{array}$ \\
\hline $\begin{array}{l}\text { 2. Menilai Secara berkala efektivitas } \\
\text { mekanisme, dan dari hasil, komunikasi } \\
\text { dengan pemangku kepentingan } \\
\text { (stakeholder) ekstemal dan intemal. }\end{array}$ & $\begin{array}{l}\text { Membuat jadwal penilaian efektivitas secara } \\
\text { rutin, agar selalu ada komunikasi dengan } \\
\text { stakeholder intemal dan ekstemal. Dapat } \\
\text { dilakukan dengan rapat untuk berkomunikasi } \\
\text { dengan pemangku kepentingan untuk menilai } \\
\text { efektivitas mekanisme tersebut }\end{array}$ \\
\hline $\begin{array}{l}\text { 3. Tentukan apakah persyaratan pemangku } \\
\text { kepentingan (stakeholder) yang berbeda } \\
\text { terpenuhi. }\end{array}$ & $\begin{array}{l}\text { Selalu menjalin komunikasi dengan pemangku } \\
\text { kepentingan agar keinginan dari pemangku } \\
\text { kepentingan dapat terpenuhi. }\end{array}$ \\
\hline
\end{tabular}

\section{KESIMPULAN}

Hasil evaluasi pengukuran capability level tata kelola dan manajemen teknologi informasi di PT Wellcomm Ritelindo Pratama menggunakan COBIT 5.0 dengan 11 proses terdapat 1 proses yang berada pada level 2 dan 10 proses berada pada level 1. Secara garis besar banyak aktifitas yang belum benar-benar dilakukan secara sepenuhnya oleh perusahaan.

Hasil rekomendasi yang diberikan berdasarkan dua target yaitu target dilakukan sepenuhnya dan target untuk dapat naik ke level berikutnya. Target dilakukan sepenuhnya diberikan agar perusahaan dapat melakukan tiap aktifitas dan menyelesaikannya hingga dapat dikatakan aktifitas tersebut dilakukan sepenuhnya.

\section{DAFTAR PUSTAKA}

Gondodiyoto, Santoyo. (2007). Audit Sistem

Informasi: Pendekatan COBIT, Edisi Revisi, Jakarta: Mitra Wacana Media.

ISACA. (2012). A Business Framework for the Governance and Management of Enterprise IT. United States of America.

ISACA. (2013). Process Assessment Model (PAM): Using COBIT® 5. United States of America.

ISACA. (2013). Assessor Guide : Using COBIT® 5. Unites Stated of America. 